\title{
EFFECT OF METABOLIC INHIBITION ON SODIUM ION EXCHANGE IN THE VENTRAL NERVE CORD OF MELANOPLUS DIFFERENTIALIS*
}

\author{
D. J. WEIDLER, A. M. EARLE, G. G. MYERS and P. J. GARDNER
}

Department of Physiology and Biophysics and Department of Anatomy, College of Medicine, The University of Nebraska, Omaha, Nebraska; and the Upjohn Center for Clinical Pharmacology, The University of Michigan Medical Center, Ann Arbor, Michigan 48104, U.S.A.

(Received 29 August 1973)

\begin{abstract}
Radioisotopic studies with ${ }^{22} \mathrm{Na}$ were conducted in vitro on nerve cords of the grasshopper Melanoplus differentialis.

2. The total uptake of ${ }^{22} \mathrm{Na}$ by nerve cords is significantly decreased by the presence of $5 \mathrm{mM}$ azide in the incubation medium.

3. Six components were extracted from desaturation curves of nerve cords, after which some residual radioactivity remained in the majority of cases.

4. The size of the third efflux component is decreased significantly and that of the fourth efflux component is increased significantly by metabolic inhibition during incubation.

5. It was concluded that the intact nerve cord of $M$. differentialis actively absorbs $\mathrm{Na}^{+}$from the bathing medium.
\end{abstract}

\section{INTRODUCTION}

Some herbivorous insects have a very low hemolymph $\mathrm{Na}^{+}$concentration (Duchâteau et al., 1953; Sutcliffe, 1963). It is generally agreed that active absorption of $\mathrm{Na}^{+}$by the nervous system of these insects exists, and results in an increase in $\mathrm{Na}^{+}$concentration of the fluid immediately surrounding axons relative to the hemolymph $\mathrm{Na}^{+}$concentration (Treherne, 1965, 1967, 1972; Treherne \& Maddrell, 1967; Weidler \& Diecke, 1969, 1970a, b). Until the present time, the only insect species with unusual hemolymph ionic concentrations whose nerve cords have been studied with radiosodium are Carausius morosus (Treherne, 1965; Weidler \& Diecke, 1970a) and Diapheromera femorata (Weidler \& Diecke, 1970b). In these studies, it was shown that the total $\mathrm{Na}^{+}$uptake by the nerve cord was decreased significantly by the presence of a metabolic inhibitor in the incubation medium.

* This work was supported by USPHS Institutional Research Support Grant No. FR 5391 to The University of Nebraska College of Medicine and USPHS Grant No. 5 P11 GM15559 to the Upjohn Center for Clinical Pharmacology, The University of Michigan Medical Center. Reprint requests should be sent to D. J. Weidler, Upjohn Center for Clinical Pharmacology, The University of Michigan Medical Center, Ann Arbor, Michigan 48104, U.S.A. 
Although the commonly used compartmental methods of kinetic analysis were employed in these studies (Treherne, 1965; Weidler \& Diecke, 1970a, b), it was recently shown that there were certain defects in the experimental design of these radioisotopic studies, and that the resulting component analysis was faulty (Weidler et al., 1971). However, despite these defects it is clear that active $\mathrm{Na}^{+}$absorption occurs in the nerve cords of $C$. morosus and $D$. femorata because total uptake values are not dependent on the methods of component analysis.

In the present work the effect of metabolic inhibition on $\mathrm{Na}^{+}$absorption by the nerve cord of $\boldsymbol{M}$. differentialis was investigated; this species was selected because it has a hemolymph $\mathrm{Na}^{+}$concentration of $64.9 \mathrm{mM}$ (Weidler et al., 1973). Since $M$. differentialis has a relatively low hemolymph $\mathrm{Na}^{+}$concentration, we hypothesize that $\mathrm{Na}$ ions are absorbed actively into the extracellular fluid which surrounds the neurons in the nerve cord; such a transport mechanism would result in an elevated $\mathrm{Na}^{+}$concentration in the extracellular fluid relative to the hemolymph, and may occur via an active transport system located in the neural sheath complex. To test this hypothesis, we utilized the revised experimental design for radioisotopic studies on the insect nerve cord described by Weidler et al. (1971).

\section{MATERIALS AND METHODS}

Many of the methods utilized in this study were used previously (Weidler \& Diecke, 1970a, b; Weidler et al., 1971); therefore only deviations from previous methods will be described in detail. Adult female Melanoplus differentialis, which were used in the present study, were collected from the Missouri River Valley near Omaha, Nebraska, and maintained in the laboratory on a diet of bluegrass.

The physiological solution had the following composition (concentrations in $\mathrm{mM}$ ): $\mathrm{Na}^{+}$ $15 ; \mathrm{K}^{+} 5 ; \mathrm{Ca}^{2+} 8 ; \mathrm{Mg}^{2+} 15 ; \mathrm{Cl}^{-} 240$; Tris 206. Tris refers to Tris (hydroxymethyl) aminomethane. Tris- $\mathrm{HCl}$ buffer was used to maintain the $\mathrm{pH}$ at $7 \cdot 4$, and to elevate the osmotic concentration to the desired level. Although the normal hemolymph $\mathrm{Na}^{+}$concentration in $M$. differentialis is $64.9 \mathrm{mM}$ (Weidler et al., 1973), a solution containing only $15 \mathrm{mM} \mathrm{Na}{ }^{+}$was utilized in the present study to exaggerate the effect of an active $\mathrm{Na}^{+}$ uptake mechanism which might be present. In experiments where metabolic inhibition was desired, the normal physiological solution was altered by replacing $5 \mathrm{mM} \mathrm{NaCl}$ with $5 \mathrm{mM}$ sodium azide $\left(\mathrm{NaN}_{3}\right)$.

To initiate experiments the whole nerve cord was dissected from freshly decapitated insects, and all layers of the neural sheath complex were allowed to remain intact. Both ends of the nerve cord were ligated with a fine silk thread; no attempt to ligate peripheral nerves was made. However, the peripheral nerves were dissected out to as great a length as practical in order to reduce free diffusion from their cut ends.

After incubation in the radioactive solution, nerve cords were carefully blotted on filter paper, and washed in successive $2-\mathrm{ml}$ volumes of solution in planchets according to the following schedule. The nerve cord was left for $5 \mathrm{sec}$ in each of the first two planchets containing physiological solution, $10 \mathrm{sec}$ in the next seven planchets, $20 \mathrm{sec}$ in the next eight planchets, $1 \mathrm{~min}$ in the next four planchets, 2,4 and $6 \mathrm{~min}$ in the next three planchets respectively, $10 \mathrm{~min}$ in the next four planchets, $15 \mathrm{~min}$ in the next two planchets, $30 \mathrm{~min}$ in the next eleven planchets, $1 \mathrm{hr}$ in the next three planchets, $2 \mathrm{hr}$ in the next six planchets and $3 \mathrm{hr}$ in the last two planchets. To minimize evaporation in samples of $30 \mathrm{~min}$ duration or longer, a tightly fitting cap was placed over the planchet. Planchets subsequently were dried in an oven, and counted in a Nuclear-Chicago Corporation planchet counting system (Model 4334). After the final washing period, nerve cords were blotted again on filter paper 
and weighed. Then they were placed in a planchet, digested in a drop of concentrated nitric acid, immersed in $2 \mathrm{ml}$ of physiological solution, dried in an oven and counted in the same way as the residue from the washings. All data are expressed in the form of desaturation curves of the nerve cord; the value at each point was obtained by adding the counts $/ \mathrm{min} \cdot \mathrm{g}$ of the washings from that particular period and all subsequent periods to the final value obtained from the nerve cord itself.

\section{RESULTS}

Freshly dissected whole nerve cords from $M$. differentialis were incubated for $4 \mathrm{hr}$ in the previously described physiological solution, to which ${ }^{22} \mathrm{Na}$ had been added. There were two incubation groups; in one group, the incubation solution contained $5 \mathrm{mM}$ azide, and in the other group, no azide was present. After the incubation period, the nerve cords from both groups were washed in successive planchets for $28 \mathrm{hr}$ with physiological solution which did not contain any radiosodium. The study initially contained twenty nerve cords (i.e. ten nerve cords in each group), but the nerve cord masses varied to such a great extent that significant differences between groups were not apparent. However, when the nerve cords with masses in the relatively narrow range of $6 \cdot 11-7.95 \mathrm{mg}$ were selected, significant differences between some components were present. Six nerve cords from the metabolically inhibited group and five from the group which was not metabolically inhibited fell within this range; the desaturation data from nerve cords of each of these groups were averaged, and are plotted in Fig. 1. It was demonstrated that

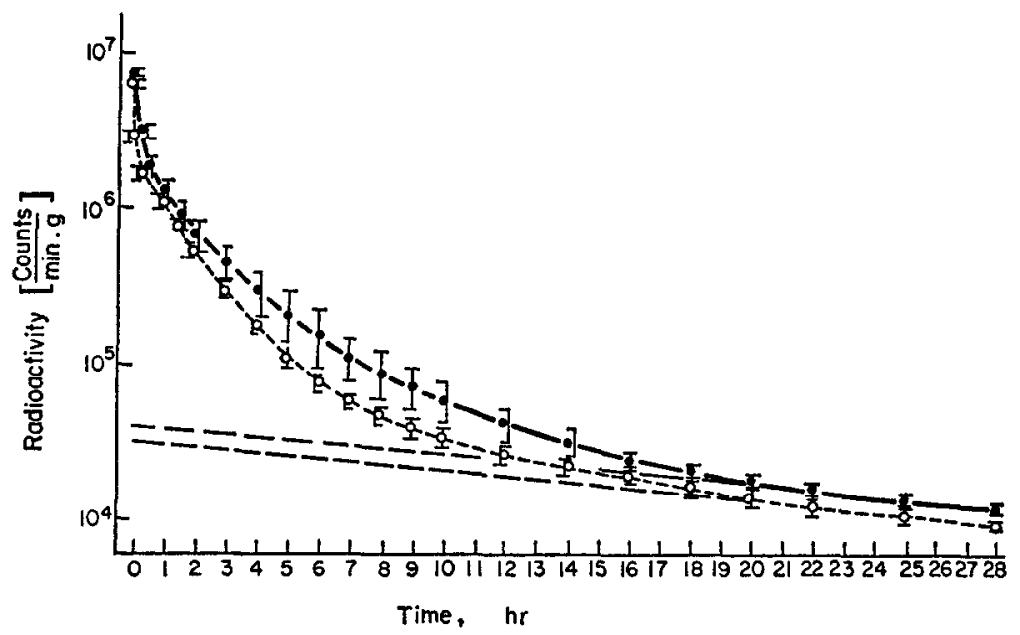

Fig. 1. Effect of metabolic inhibition on uptake and efflux of ${ }^{22} \mathrm{Na}$ in intact, whole nerve cords of $M$. differentialis. Closed circles (solid line) represent nerve cords which were not metabolically inhibited (five animals), and open circles (broken line) represent nerve cords which were metabolically inhibited during incubation (six animals). The two dashed lines are the asymptotes of their respective curves, and represent their respective sixth components. The vertical lines represent the extent of twice the standard error of the means. 
the total uptake of ${ }^{22} \mathrm{Na}$ (at zero time) by nerve cords incubated in the presence of $5 \mathrm{mM}$ azide is significantly less than the uptake obtained with nerve cords which were incubated in solutions without a metabolic inhibitor $(P<0.05)$.

The decline in radioactivity of individual nerve cords during the washout period was analyzed by the graphical method (see Solomon, 1960; Weidler et al., 1971). In this method, the components are subtracted from the original desaturation curve by beginning with the asymptote of the desaturation curve itself, which is the component having the longest half-time. We called the asymptote of the original desaturation curve the sixth component; therefore components are subtracted from the original desaturation curve in the order of sixth, fifth, fourth, etc. In the present study, component is defined as a single exponential; however, after the subtraction of all six components from the original desaturation curve, it was found that some residual radioactivity still remained in the majority of desaturation curves. The resolution of the remainder of the desaturation curves into further components is hindered by the difficulty of taking accurate samples in time periods of less than $5 \mathrm{sec}$ (Weidler et al., 1971). Using the graphical method, we found that six components are always demonstrable; their half-times were analyzed statistically and presented in Table 1. No significant differences were obtained between any of the corresponding half-times of components of nerve cords which were metabolically inhibited during incubation and those which were incubated in the absence of a metabolic inhibitor.

Table 1 -Comparison of half-times $\left(T_{\frac{1}{2}}\right)$ of THE components of $\mathrm{Na}^{+}$efFluX FROM INTACT, WHOLE NERVE CORDS AFTER A 4-hr INCUBATION PERIOD IN SOLUTION CONTAINING ${ }^{22} \mathrm{Na}$

\begin{tabular}{|c|c|c|c|}
\hline Component & $\begin{array}{c}T_{\mathrm{t}}(\text { mean } \pm \text { S.E. }): \\
\text { metabolic inhibition } \\
\text { during incubation }\end{array}$ & $\begin{array}{l}T_{\frac{1}{2}}(\text { mean } \pm \text { S.E. }): \\
\text { without metabolic } \\
\quad \text { inhibition }\end{array}$ & Significance \\
\hline First & $32 \cdot 20 \pm 19 \cdot 47 \mathrm{sec}$ & $36 \cdot 20 \pm 22.06 \mathrm{sec}$ & $P>0.80$ \\
\hline Second & $2.35 \pm 0.61 \mathrm{~min}$ & $3.13 \pm 1.67 \mathrm{~min}$ & $P>0.60$ \\
\hline Third & $18.68 \pm 6.40 \mathrm{~min}$ & $14.77 \pm 4.63 \mathrm{~min}$ & $P>0.60$ \\
\hline Fourth & $47.66 \pm 3.52 \mathrm{~min}$ & $58.66 \pm 11.53 \mathrm{~min}$ & $P>0.30$ \\
\hline Fifth & $2 \cdot 15 \pm 0.14 \mathrm{hr}$ & $2 \cdot 17 \pm 0.11 \mathrm{hr}$ & $P>0.90$ \\
\hline Sixth & $16.94 \pm 2.40 \mathrm{hr}$ & $16.83 \pm 1.22 \mathrm{hr}$ & $P>0.90$ \\
\hline
\end{tabular}

Metabolic inhibition during incubation was achieved with $5 \mathrm{mM}$ azide.

Component sizes (intercepts of components) are presented in Table 2; the data on $\mathrm{Na}^{+}$uptake from the two experimental groups (i.e. in the presence and in the absence of a metabolic inhibitor during incubation) permit only a qualitative demonstration of the effect of a metabolic inhibitor on $\mathrm{Na}^{+}$uptake rather than a quantitative determination of the $\mathrm{Na}^{+}$uptake under the two experimental conditions. The reason for this limitation is that complete saturation of nerve cords with 
TABLE 2-COMPARISON OF COMPONENT SIZES OF $\mathrm{Na}^{+}$UPTAKE IN INTACT, WHOlE NERVE CORDS AFTER A 4-hr INCUBATION IN SOLUTION CONTAINING ${ }^{22} \mathrm{Na}$

\begin{tabular}{|c|c|c|c|}
\hline Component & $\begin{array}{l}\text { Component size } \\
\qquad\left(\times 10^{5}\right): \\
\text { metabolic inhibition } \\
\text { during incubation }\end{array}$ & $\begin{array}{l}\text { Component size } \\
\quad\left(\times 10^{5}\right): \\
\text { without metabolic } \\
\text { inhibition }\end{array}$ & Significance \\
\hline First & $6 \cdot 29 \pm 2 \cdot 21$ & $10 \cdot 82 \pm 1 \cdot 54$ & $P>0 \cdot 10$ \\
\hline Second & $8.01 \pm 1.68$ & $5.56 \pm 0.45$ & $P>0.20$ \\
\hline Third & $8.09 \pm 0.92$ & $13 \cdot 17 \pm 1 \cdot 77$ & $P<0.05$ \\
\hline Fourth & $21 \cdot 06 \pm 1 \cdot 83$ & $12 \cdot 09 \pm 3 \cdot 10$ & $P<0.05$ \\
\hline Fifth & $2 \cdot 80 \pm 0 \cdot 42$ & $5 \cdot 99 \pm 2.45$ & $P>0.10$ \\
\hline Sixth & $0.34 \pm 0.07$ & $0.38 \pm 0.03$ & $P>0.60$ \\
\hline Total* & $65 \cdot 13 \pm 3 \cdot 55$ & $77 \cdot 14 \pm 3 \cdot 89$ & $P<0.05$ \\
\hline
\end{tabular}

*"Total " refers to the mean total uptake in each group; it is not simply the sum of the components since some radioactivity remains after subtraction of all six components (see text).

Component size is radioactivity in counts $/ \mathrm{min} \cdot \mathrm{g}$. Metabolic inhibition during incubation was achieved with $5 \mathrm{mM}$ azide.

radiosodium in vitro is impossible because the rate of influx of $\mathrm{Na}+$ into certain anatomical compartments is very slow, and viability declines before complete saturation can be attained. Complete saturation of the nerve cord is essential to determine the amount of $\mathrm{Na}^{+}$contained in each component (see Huxley, 1960). However, a meaningful comparison of component sizes can be made when the experimental conditions for the two groups are identical except for one variable (viz. in this case, the presence or absence of azide during the incubation period). In Table 2, it is demonstrated that there are significant differences between the group incubated in the presence of azide and that incubated in the absence of azide for the third and fourth components, but not for the other components. Furthermore, there is a significant difference in the total $\mathrm{Na}^{+}$uptake of the two groups, the mean total $\mathrm{Na}^{+}$uptake of the metabolically inhibited group being significantly smaller than that of the group incubated in the absence of the metabolic inhibitor. The total $\mathrm{Na}^{+}$uptake is not simply the sum of the six components because after all six components have been subtracted from the original desaturation curve, a variable portion remains. This remainder probably could be resolved into components if it were possible to obtain samples of less than $5 \mathrm{sec}$ in duration; however, with our methods, such a resolution was impossible.

\section{DISCUSSION}

In the present study, it was demonstrated that $\mathrm{Na}^{+}$uptake for the whole nerve cord of $M$. differentialis is decreased significantly when incubated in a solution containing a metabolic inhibitor. This result is interpreted as evidence for the existence of a mechanism for the active transport of $\mathrm{Na}^{+}$from the external bathing 
medium (hemolymph) into the extracellular fluid which immediately surrounds neurons. Two conflicting hypotheses, concerning the active absorption of $\mathrm{Na}^{+}$ by the insect nerve cord, have been proposed. One hypothesis (Treherne, 1967, 1972; Treherne \& Maddrell, 1967) states that glial cells surrounding neurons are the site of active $\mathrm{Na}^{+}$absorption. An alternative hypothesis was advanced more recently by Weidler \& Diecke $(1969,1970 \mathrm{a}, \mathrm{b})$ which proposes that the fat-body sheath in $C$. morosus is the site of active sodium absorption. Evidence for the active absorption of $\mathrm{Na}^{+}$by the fat-body sheath is based on both electrophysiological studies and radioisotopic studies (Weidler \& Diecke, 1969, 1970a, b).

Treherne (1972) recently presented evidence that the fat-body sheath is rather leaky after it has been displaced from a connective, the neural lamella and perineurium removed, and the fat-body sheath once more placed in its proper position. On the basis of this observation, he concluded that the neural fat-body sheath is unlikely to be involved in the regulation of the extra-neuronal $\mathrm{Na}^{+}$concentration. However, the temporary displacement of the fat-body sheath certainly may cause the fat-body sheath to become abnormally permeable in the absence of anatomical changes, and the high degree of permeability itself certainly does not rule out the possibility that the fat-body sheath may be the site of active transport.

Other evidence against the fat-body sheath as the site of active $\mathrm{Na}^{+}$absorption is the observation that particles as large as indian ink and peroxidase (mol. wt. 40,000 ) can penetrate the fat-body sheath (Lane \& Treherne, 1971). However, the peroxidase molecule and $\mathrm{Na}^{+}$have very little in common structurally; and unless simple unrestricted passive diffusion is assumed to be the only transport mechanism available, there is no reason to suppose that the transport mechanisms for both molecules are the same. With the exception of certain gases and highly lipid soluble substances, it is difficult to conceive of any molecule passing rapidly across such a complex structure as the fat-body sheath by simple unrestricted passive diffusion.

Another argument against the fat-body sheath hypothesis is that this structure is absent from the peripheral nervous system in $C$. morosus. Recent evidence obtained with electron microscopy in Periplaneta americana (Gardner \& Weidler, 1971 ) indicates that the basement membrane of the fat body is continuous over the neural lamella in areas of the nerve cord where the fat body apparently is absent. This anatomical relationship probably is present also in the peripheral nerves of $C$. morosus; it is the basement membrane of the fat-body sheath which Weidler \& Diecke $(1970 \mathrm{a}, \mathrm{b})$ proposed as the site of active $\mathrm{Na}^{+}$absorption. This structure may be present in the peripheral nervous system of $C$. morosus as well as $P$. americana, and could be the structural substrate for active $\mathrm{Na}^{+}$absorption.

Treherne (1972) did not consider two important pieces of evidence in favor of the fat-body sheath as the site of active $\mathrm{Na}^{+}$absorption. First, the viability of nerve cords bathed in solutions with low $\mathrm{Na}^{+}$concentrations is decreased significantly when small areas of the fat-body sheath are removed (Weidler \& Diecke, 1969). Second, active $\mathrm{Na}^{+}$absorption by the nerve cord ceases when the fat-body sheath is removed (Weidler \& Diecke, 1970a). We are of the opinion that the evidence of 
Weidler \& Diecke $(1969,1970 \mathrm{a}, \mathrm{b})$ more strongly supports the fat-body sheath hypothesis than that which Treherne (1972) presents against it, because the former studies involved less surgical manipulation of the preparation, upon which measurements were made.

At the present time, it still seems reasonable to interpret the existing data in terms of an active transport system located in the fat-body sheath as proposed by Weidler \& Diecke $(1969,1970 \mathrm{a}, \mathrm{b})$. The definitive experiment which ultimately will decide the issue is the measurement of fluxes with radiosodium in both directions across the neural sheath complex in the intact nerve cord. Such an experiment is indeed difficult, but not impossible to perform with available technology.

Recent studies on $M$. differentialis (Weidler et al., 1973) demonstrated a so-called tracheolated membrane or fat-body sheath in this species. Therefore, it follows from the above discussion that it is possible that the tracheolated membrane or fat-body sheath in $M$. differentialis is the site of the active $\mathrm{Na}^{+}$absorption which was demonstrated in the present study. There presently is no way to ascertain the origin of the various components in the desaturation curves. However, we hypothesize that the third component comes from the extracellular fluid of the nerve cord, from within the confines of the neural lamella and perineurium, and that the fourth component represents $\mathrm{Na}^{+}$from the intracellular fluid of neurons and glial cells within the nerve cord. The fifth and sixth components may have their origin in subcellular units, such as mitochondria; the sixth component, which is very small in size compared to the other components, may represent so-called bound $\mathrm{Na}^{+}$. The second component may originate intracellularly in the fat-body cells, and the first component may arise from the surface of the nerve cord.

We hypothesize that active $\mathrm{Na}^{+}$absorption normally occurs across the tracheolated membrane and that, as a result, the $\mathrm{Na}^{+}$concentration of the extracellular fluid (third component) is higher than that of the hemolymph. Based on this hypothesis, it would be predicted that the third component should decrease significantly when the nerve cord is metabolically inhibited; this is what was observed in the present study. Furthermore, we hypothesize that the fourth component has its origin intracellularly in neurons and glial cells; it would be predicted that this component should increase significantly when the nerve cord is metabolically inhibited because of blockage of the $\mathrm{Na}^{+}$pump in the cellular membranes. Again, this is what actually was observed in the present study.

The significance of the present work is that it demonstrates the active absorption of $\mathrm{Na}^{+}$by the intact nerve cord of $M$. differentialis; this species is similar to $C$. morosus and $D$. femorata in both the presence of active $\mathrm{Na}^{+}$absorption by the nerve cord and the relatively low $\mathrm{Na}^{+}$concentration in the hemolymph. It appears that active $\mathrm{Na}^{+}$absorption by the nerve cord is the mechanism whereby the $\mathrm{Na}^{+}$ concentration of the extracellular fluid surrounding neurons is elevated above that which is present in the hemolymph. At the present time, the most likely site for $\mathrm{Na}^{+}$absorption appears to be the neural sheath complex, and more specifically, $\mathrm{Na}$ ions probably are absorbed by the tracheolated membrane. 


\section{REFERENCES}

Duchâteau G., Florkin M. \& Leclerce J. (1953) Concentrations des bases fixes et types de composition de la base totale de l'hémolymphe des insectes. Archs int. Physiol. 61, 518-549.

Gardner P. J. \& WeIdLer D. J. (1971) Preliminary observations on the ultrastructure of the neural sheath complex in the cockroach, Periplaneta americana. Anat. Rec. 169, 322-323.

Huxley A. F. (1960) Appendix 2 of Chapt. 5. In Mineral Metabolism (Edited by Comar C. L. \& Bronner F.), Vol. 1, part A, pp. 163-166. Academic Press, New York.

Lane N. J. \& Treherne J. E. (1971) The distribution of the neural fat body sheath and the accessibility of the extraneural space in the stick insect, Carausius morosus. Tissue \& Cell 3, 589-603.

Solomon A. K. (1960) Compartmental methods of kinetic analysis. In Mineral Metabolism (Edited by Comar C. L. \& Bronner F.), Vol. 1, part A, pp. 119-167. Academic Press, New York.

SuTCLIFFE D. W. (1963) The chemical composition of haemolymph in insects and some other arthropods in relation to their phylogeny. Comp. Biochem. Physiol. 9, 121-135.

TREHERNE J. E. (1965) The distribution and exchange of inorganic ions in the central nervous system of the stick insect Carausius morosus. F. exp. Biol. 42, 7-27.

Treherne J. E. (1967) Axonal function and ionic regulation in the insect central nervous tissues. In Insects and Physiology (Edited by Beament J. W. L. \& Treherne J. E.), pp. 175-188. Oliver \& Boyd, Edinburgh.

Tremerne J. E. (1972) A study of the function of the neural fat-body sheath in the stick insect, Carausius morosus. F. exp. Biol. 56, 129-137.

Treherne J. E. \& Maddrell S. H. P. (1967) Axonal function and ionic regulation in the central nervous system of a phytophagous insect (Carausius morosus). $\mathcal{F}$. exp. Biol. 47, 235-247.

WeIdleR D. J. \& Diecke F. P. J. (1969) The role of cations in conduction in the central nervous system of the herbivorous insect Carausius morosus. Z. vergl. Physiol. 64, 372-399.

Weidler D. J. \& Diecke F. P. J. (1970a) The regulation of sodium ions in the central nervous system of the herbivorous insect Carausius morosus. Z. vergl. Physiol. 67, $160-178$.

Weidler D. J. \& Diecke F. P. J. (1970b) Hemolymph ionic concentrations and sodium ion regulation by the neural sheath in two stick insect species (Diapheromera femorata and Carausius morosus). Z. vergl. Physiol. 69, 311-325.

Weidler D. J., Gardner P. J., Earle A. M. \& Myers G. G. (1973) The suitability of Melanoplus differentialis for electrophysiological investigation based on hemolymph ionic and anatomical studies. Comp. Biochem. Physiol. 44A, 807-812.

Weidler D. J., Myers G. G., Gardner P. J., BennetT A. L. \& Earle A. M. (1971) Defects in the experimental design of radioisotopic studies on the insect nerve cord. $Z$. vergl. Physiol. 75, 352-366.

Key Word Index-Grasshopper; Melanoplus differentialis; active $\mathrm{Na}^{+}$transport; ventral nerve cord; component analysis; ionic exchange; low hemolymph $\mathrm{Na}^{+}$. 